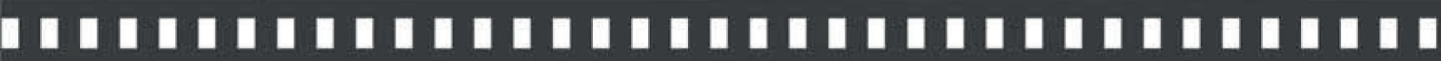

\section{Fotojornalismo: entre o oblíquo e o referencial}

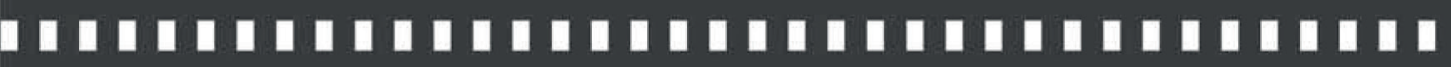

Jaqueline Esther Schiavoni

Artigo recebido em: 04/04/2016

Artigo aprovado em: 21/04/2017 


\title{
Fotojornalismo: entre o oblíquo e o referencial
}

\author{
Photojournalism: between the oblique and the referential
}

Jaqueline Esther Schiavoni*

Resumo: Este texto tem por objeto de reflexão a imagem Touché, de Wilton Junior, vencedora da $57^{a}$ edição do Prêmio Esso de Jornalismo, na categoria Fotografia. As análises tomam em consideração autores como Roland Barthes, Jean-Marie Floch e Jacques Fontanille para explicitar a problemática em torno do sentido da referida imagem e de sua publicação no jornal Estado de S. Paulo.

Palavras-chave: Fotografia. Oblíquo. Referencial. Semiótica francesa.

\begin{abstract}
This paper has as object of reflection the image Touché, from Wilton Junior, winner of the 57th edition of Esso Journalism Award, in Photography category. The analysis take into account authors such as Roland Barthes, Jean-Marie Floch and Jacques Fontanille to explain the problematic about the meaning of the referred image and its publication in the newspaper Estado de S. Paulo.
\end{abstract}

Keywords: Photography. Oblique. Reference. French semiotics.

*Doutora em Meios e Processos Audiovisuais (ECA-USP). Estágio pós-doutoral na Unesp, em Comunicação Midiática. Desenvolve estudos sobre a imagem a partir dos aportes teóricos e metodológicos da semiótica francesa. 
[...] Não sei o que a sociedade faz de minha foto, o que ela lê nela (de qualquer modo, há tantas leituras de uma mesma face); mas quando me descubro no produto dessa operação, o que vejo é que me tornei Todo-Imagem, isto é, a Morte em pessoa; os outros - o Outro - desapropriamme de mim mesmo, fazem de mim, com ferocidade, um objeto, mantêm-me à mercê, à disposição, arrumado em um fichário, preparado para todas as trucagens sutis [...]. (Roland Barthes, 1984, p. 29).

O momento era solene. A foto também deveria ser. Mas não foi bem assim que aconteceu. $\mathrm{O}$ episódio em questão data de agosto de 2011 e envolve a cerimônia de entrega de espadins para 441 cadetes do primeiro ano da escola de formação oficial. Tratava-se, evidentemente, de um evento emblemático, com direito a honras militares de gala e tiros de canhão - 21 ao todo. A homenageada era a presidenta Dilma, mas quem deu mesmo o que falar foi o fotógrafo - Wilton Junior, à serviço do jornal O Estado de S. Paulo - que num "click" fez um registro um tanto inusitado para a ocasião. Figura 1 - Touché, de Wilton Junior, vencedor da $57^{a}$ edição do Prêmio Esso de Jornalismo, na categoria Fotografia

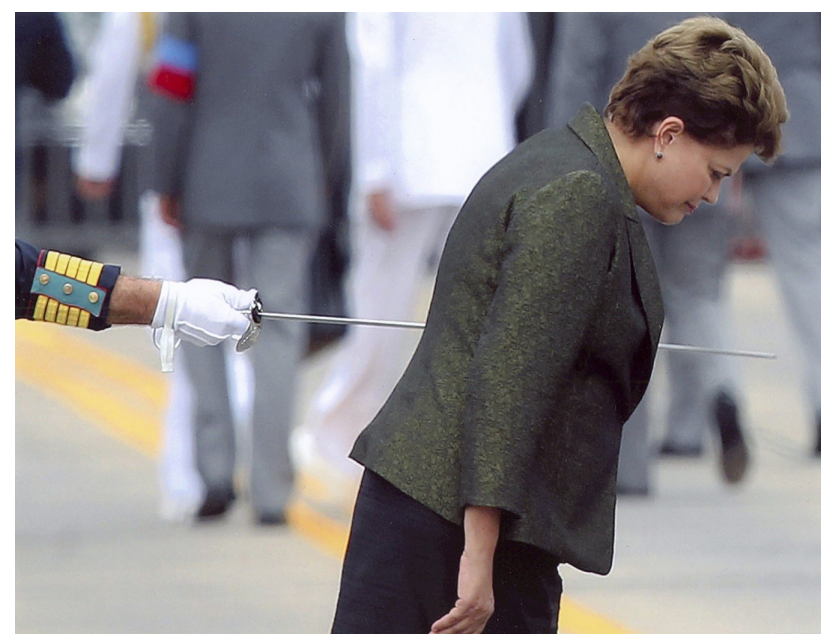

Foto: Domingos (2011) 
A imagem gerou polêmica à época. Em blogs e redes sociais, alguns elogiaram o retrato e o brilhantismo da atuação do profissional. Outros criticaram o trabalho, apontando a falta de decoro do repórter fotográfico e a construção tendenciosa do jornal, que publicou a imagem numa espécie de "link" com outras notícias sobre política (Figura 2) - aspecto que abordaremos mais adiante. Houve até quem afirmasse que a imagem da presidenta Dilma sendo transpassada pelo espadim de um cadete da Academia Militar das Agulhas Negras (Aman) não passava de fotomontagem. Para estes últimos, o fotógrafo postou no blog do Estadão a sequência original das imagens que tirou e algumas delas estão dispostas logo a seguir (Figura 3).

Figura 2 - Diagramação

Descontentes com tratamento do PT e receosos sobre empenho da presidente para manter aliança, dirigentes preparam candidaturas

João Domingos / BRASÍLIA

Nas reuniões com dirigentes estaduais e municipais do PMDB Brasil afora, o presidente interino do partido, senador Valdir Raupp (RO), insiste em dizer que todos devem estarpreparados para a possibilidade de trabalhar por um candidato da legenda à sucessão da presidente Dilma Rousseff.

"Nós temos de construir nomesparaasucessãoem 2014", disse Raupp ao Estado. "Temos vários, mas outros podem surgir." Os peemedebistas, quejá se movimentam para 2014, têm três nomes neste momento. Um deles é o do vice Michel Temer (SP). Os outros sãoos do ex-ministro Nelson Jobim (Defesa) edo governador do Rio, Sérgio Cabral.

Por trás dessa defesa da candidatura própria há dois recados do PMDB. Um, dirigido aos peemedebistas descontentes com a forma como julgam estar sendo

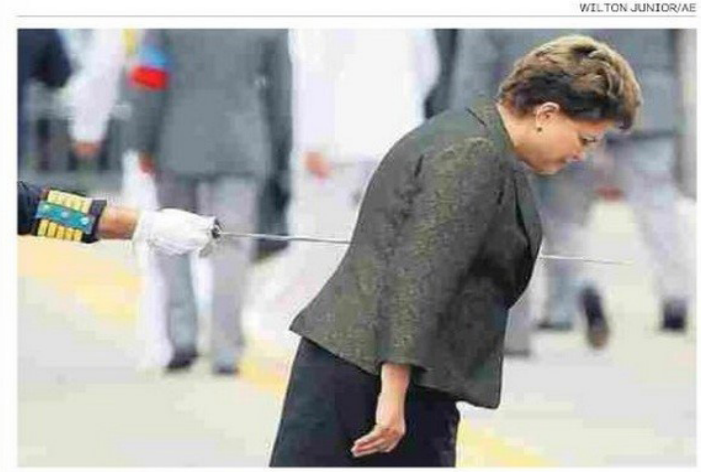

(iin)

\section{Honras militares}

Recebida em solenidade de gala, na Academia de Agulhas Negras, a presidente Dilma Rousseff assistiu ontem à entrega de espadins a 441 cadetes que cursam o primeiro dos quatro anos da escola de formação de oficiais.

Foto: Domingos (2011) 
Figura 3 - Sequência Touché.
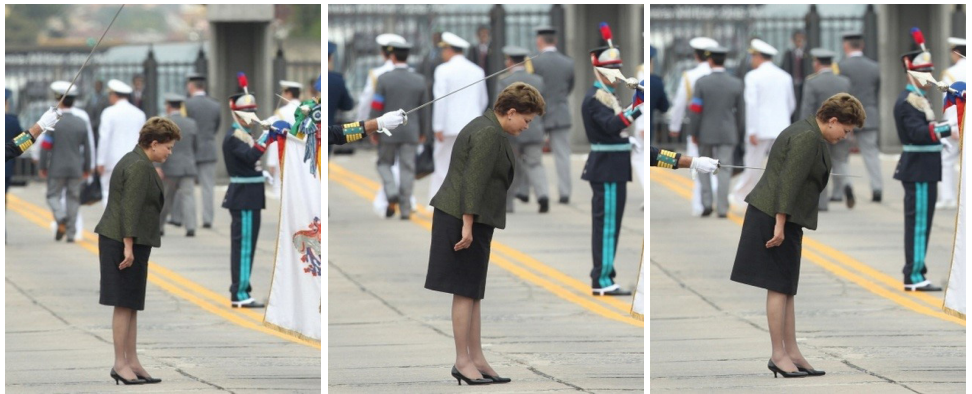

Seleção de imagens da sequência original de fotos postadas por Wilton Junior no blog do Estadão acerca de Touché, vencedora da $57^{\mathrm{a}}$ edição do Prêmio Esso de jornalismo, na categoria Fotografia.

Foto: Domingos (2011)

Conhecidos os registros, como avaliar em termos teóricos o debate levantado pela imagem? Como explicar a polêmica, a participação de ataque e defesa (quase sempre apaixonada) dos leitores da notícia? Roland Barthes, que se deteve em estudos sobre a fotografia, escreveu sobre o efeito que certas imagens the causavam:

Muitas fotos, infelizmente, permanecem inertes diante de meu olhar. Mas mesmo entre as que têm alguma existência a meus olhos, a maioria provoca em mim apenas um interesse geral e, se assim posso dizer, polido: nelas, nenhum punctum: agradam-me ou desagradamme sem me pungir: estão investidas somente do studium (BARTHES, 1984, p. 47).

O studium e punctum dos quais nos fala o teórico francês parecem ser dois conceitos fundamentais para entender a questão em torno da foto da presidenta Dilma. O primeiro, o studium, envolve um trabalho cognitivo de reconhecimento, que implica distinguir o sujeito, as ações, o cenário retratado na foto e assim por diante. Em outras palavras, envolve reconhecer o contexto em 
que a imagem se insere. E, para isso, é preciso ter certa medida de conhecimento histórico e referência cultural. Muitas das fotos vistas por Barthes, conforme apontado na citação anterior, eram dotadas apenas de studium. O que interessa particularmente para este estudo é saber um pouco mais sobre a reação que essas fotos causavam no teórico. Ele próprio explica:

O que experimento em relação a essas fotos tem a ver com um afeto médio, quase como um amestramento. Eu não via, em francês, palavra que exprimisse simplesmente essa espécie de interesse humano; mas em latim, acho que essa palavra existe: é o studium, que não quer dizer, pelo menos de imediato, 'estudo', mas a aplicação a uma coisa, o gosto por alguém, uma espécie de investimento geral, ardoroso, é verdade, mas sem acuidade particular. É pelo studium que me interesso por muitas fotografias, quer as receba como testemunhos políticos, quer as aprecie como bons quadros históricos: pois é culturalmente (essa conotação está presente no studium) que participo das figuras, das caras, dos gestos, dos cenários, das ações (BARTHES, 1984, p. 45).

O "afeto médio" do público, próprio do studium, parece ter sido o que obtiveram as fotos das mídias concorrentes - assim depreendemos em função da inexistência de comentários públicos dirigidos a tais imagens, diferentemente do que ocorreu com a foto de Wilton Junior. Tudo indica que o leitor, em geral, correu os olhos pela página e não teve pelas outras imagens mais que um interesse "vago", "uniforme" e "irresponsável" - para citar alguns dos termos que Barthes utiliza ao descrever seu sentimento em torno de imagens dotadas apenas de studium.

Para fornecer uma ideia do que isso significa em relação ao objeto que está sendo abordado neste trabalho dispomos adiante algumas das fotos publicadas em outros veículos jornalísticos - site do Planalto (STUCKERT FILHO, 2011), da Voz da Cidade (de Barra Mansa, no Rio de Janeiro) e do G1 (TABAK, 2011) - acerca 
do mesmo evento, a cerimônia de entrega de espadins aos cadetes do primeiro ano da escola de formação de oficiais da Academia Militar das Agulhas Negras, no Rio de Janeiro. Empresas como a Folha de S. Paulo, Correio Brasiliense e Zero Hora não dispuseram de matéria com foto em suas homepages.

Figura 4 - Cerimônia Aman

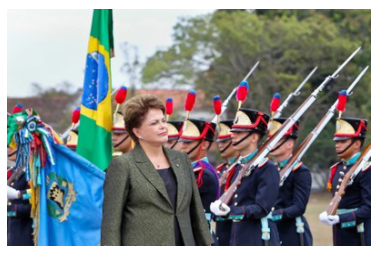

Planalto

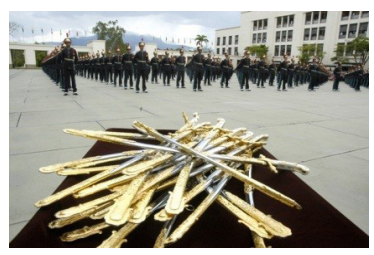

Voz da Cidade

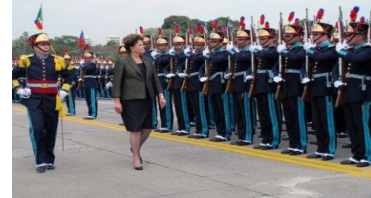

G1

As fotos, como se pode notar, seguem o protocolo. É possível que alguma das informações contidas em cada uma das imagens tenha despertado a curiosidade do leitor: talvez a forma e o material de que são feitas as espadas, a organização e a vestimenta dos cadetes, o penteado da presidenta ou mesmo o fato de ser uma mulher a chefe de Estado. Mas isso não quer dizer que o sujeito que olha foi de fato tocado pela foto. Se algum leitor se sente compungido ao vê-las - e isso pode acontecer, afinal, como dizia Barthes, a fotografia é sempre contingente - é provável que haja na história desse sujeito qualquer ligação com o tema da foto ou algum de seus elementos.

Esse "sentir-se tocado" é o que Barthes chamou de punctum. Em contato com uma imagem, o leitor pode ser despertado emocionalmente por qualquer elemento da fotografia, e sentir-se sensibilizado intensamente - em gozo ou dor. $\mathrm{O}$ autor explica o conceito em mais detalhes:

$\mathrm{O}$ segundo elemento vem quebrar (ou escandir) o studium. Dessa vez, não sou eu que vou buscá-lo (como invisto com minha consciência soberana o campo do 
studium), é ele que parte da cena, como uma flecha, e vem me transpassar. Em latim existe uma palavra para designar essa ferida, essa picada, essa marca feita por um instrumento pontudo; essa palavra me serviria em especial na media em que remete também à idéia de pontuação e em que as fotos de que falo são, de fato, como que pontuadas, às vezes até mesmo mosqueadas, com esses pontos sensíveis; essas marcas, essas feridas são precisamente pontos. A esse segundo elemento que vem contrariar o studium chamarei então punctum; pois punctum é também picada, pequeno buraco, pequena mancha, pequeno corte - e também lance de dados. $\mathrm{O}$ punctum de uma foto é esse acaso que, nela, me punge (mas também me mortifica, me fere) (BARTHES, 1984, p. 46).

E foi assim - feridos - que se sentiram muitos que viram a foto da presidenta. Segundo Barthes, o punctum é algo absolutamente pessoal, quer dizer, depende única e exclusivamente da subjetividade do leitor que observa a imagem. No entanto, acreditamos que algumas condições podem "predispor" ou "disparar", por assim dizer, esse sentido emocional no sujeito. Do contrário, as outras fotos publicadas sobre o evento no Rio de Janeiro também teriam sido comentadas, mesmo que em menor quantidade ou ardor, mas ainda assim comentadas com algum afeto - afinal, trata-se do mesmo evento, mesmos personagens e mesmo cenário. Mas isso não aconteceu.

Que condições, então, poderiam ter sido responsáveis por "disparar" o sentido emocional no sujeito? O próprio Roland Barthes faz um levantamento de tipos de fotografia que, apesar de não conterem a priori nenhum punctum, são capazes de causar um "choque" em quem olha, cenas que apresentam o que ele chama de "surpresas que obedecem a um princípio de desafio" (BARTHES, 1984, p. 56.). O autor lista: a raridade de um evento; a apreensão de uma cena rápida em seu tempo decisivo; a proeza da fotografia (quando se trata de algum tipo de registro avançado para a época); 
as contorções da técnica; e, por fim, o achado - categoria em que bem poderia se encaixar a foto tirada por Wilton Junior, dada a colocação do fotojornalista no "lugar certo" e na "hora certa", como se costuma dizer (BARTHES, 1984, p. 54-57).

Mas para a obtenção desse "achado" fotográfico foi preciso também a "técnica certa". Conforme explica a revista Photo Magazine sobre o "click" em questão, "a imagem é fruto de uma característica física das teleobjetivas de longo alcance, que 'achatam' os planos, aproximando-os" (PHOTO MAGAZINE, 2011, p. 73). É esse efeito técnico o responsável pela duplicidade de sentido da imagem e, em certa medida, pelo punctum geral causado pela fotografia. Mas, por que se pode dizer isso?

Como se sabe, o advento da fotografia foi um momento ímpar na história da representação plástica, já que com ela a produção de uma imagem não precisava emergir mais da subjetividade de seu criador, como acontecia na prática do desenho ou da pintura. Antes, estava fora do sujeito e das deformações que sua sujetividade imputava à imagem, pois passava a ser apreendida da própria realidade por um processo de registro automatizado. A objetividade que esse dispositivo conseguia alcançar na representação da imagem era - como ainda é considerado hoje em dia por muitos inquestionável, já que cada ponto representado tinha sua pregnância no real, uma vez que se tratava da própria realidade projetada de forma invertida na parede fotossensível da câmera.

Em razão disso, a fotografia sempre teve o status de imagemdocumento, motivo pelo qual foi amplamente utilizada em jornais e revistas, já que era ela mesma a prova contundente de que tudo o que tinha sido registrado havia realmente ocorrido. Uma espécie de garantia, de evidência da preexistência da coisa fotografada. Quando Wilton Junior faz o "click" achatando os planos e propõe a construção de um sentido que não revela nem de perto qualquer aproximação com a realidade, afinal em momento algum a vida da presidenta Dilma esteve sob ameaça nessa ocasião, o fotógrafo quebra o contrato - de veridicção e fidúcia - com o leitor. E nisso, 
acreditamos, está em parte o punctum da imagem.

Para explicitar melhor essa problemática recorreremos a um dos trabalhos desenvolvidos por Jean-Marie Floch (1990) em Semiotique, marketing et communication - sous les signes, les estratégies. Trata-se do capítulo intitulado Tués dans l'oeuf! Apesar de ser um texto dedicado a análise de peças publicitárias, as considerações tecidas nele podem ser aplicadas a objetos de outras áreas, como a fotografia. Conforme mostra o autor, valores bem definidos costumam marcar as obras das boas agências de publicidade, garantindo-lhes um perfil fácil de ser reconhecido no mercado, uma identidade. Esses valores, via de regra, oscilam entre o que ele chama de função representativa e função criativa. Em outras palavras, uma oposição entre os valores inerentes a um determinado produto e os valores que a publicidade cria para ele.

Projetada num quadrado semiótico, a categoria levantada por Floch se desdobra em quatro tipos de produtos publicitários que ele denominou de referencial, mítico, substancial e oblíquo:

\section{FUNÇÃO REPRESENTATIVA $\quad$ FUNÇÃO CRIATIVA}

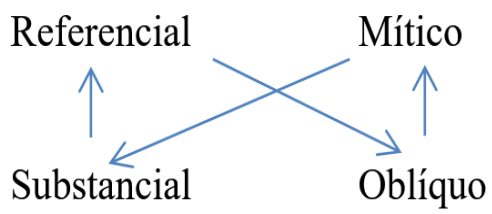

Grosso modo, enquanto a publicidade referencial se projeta sobre a realidade, como uma reconstituição dela, a publicidade oblíqua é a sua negação. De modo que a primeira se pauta pelo sentido dado, determinado e acabado; e a outra pelo sentido sempre pronto a ser construído com a ajuda do sujeito que a interpreta. Já na publicidade mítica o que se tem é uma espécie de reorganização do sentido pelo discurso, que pode valer-se da bricolagem de símbolos e referências culturais populares e a exploração de valores semânticos opostos. Em negação a isso está a publicidade 
substancial, que prima pela valorização das qualidades essenciais do produto que anuncia, em vez do sonho e da fantasia que caracterizam a publicidade mítica.

Com base nessa breve retomada conceitual, é fácil perceber que a foto de Wilton Junior se insere no que Floch (1990) denominou de oblíquo. O que o efeito técnico de achatamento dos planos faz é justamente criar uma espécie de desvio de leitura, um jogo de sentido, uma ambiguidade que terá de ser resolvida, por assim dizer, pelo leitor - que pode aceitar ou não a proposta, de acordo com a seriedade com que ele se coloca diante da imagem e da confiança que ele credita ao dispositivo fotográfico.

A razão pela qual o quadrado semiótico formulado por Floch (1990) foi evocado neste trabalho diz respeito ao mérito que o arranjo tem em nos permitir identificar com clareza onde se situa a problemática em torno da fotografia de Wilton Júnior, quer dizer, onde se situa o referencial e o oblíquo, bem como a relação de negação que este último tem com o primeiro. Assim, enquanto as fotos dos outros profissionais cumpriam com o ritual da referencialidade fotográfica, a foto de Wilton Junior tratava de trair todos esses pressupostos. Os jornais concorrentes tinham, portanto, uma imagem que correspondia a tudo o que se pode esperar de um aparato automático de registro: um dispositivo referencial e uma imagem referencial. O Estadão, por sua vez, tinha uma imagem que subvertia o meio: um dispositivo referencial e uma imagem oblíqua.

Todas essas considerações, entretanto, ainda não explicam por completo a pre-disposição do público ao punctum. Recorrendo aos desenvolvimentos teóricos de outro francês, Jacques Fontanille (2005), percebe-se que tão importante quanto os signos (aspectos plásticos e figurativos da imagem), os textos-enunciados (reconhecimento e interpretação das figuras semióticas num todo organizado) e os objetos (a fotografia como suporte de inscrição da luz) - que de certa forma foram abordados até o momento são também as situações semióticas, quer dizer, o lugar onde se 
encontra a fotografia e tudo o que se coloca em seu entorno.

Fontanille (2005) explica a relação entre esses níveis de pertinência semiótica a partir da afixagem de cartaz - outro exemplo retirado da área de publicidade e propaganda, mas que fornecerá contribuições ao objeto deste estudo. Conforme argumenta o teórico, não só a morfologia do objeto-suporte interfere ou gera significação, configurando uma prática mais ou menos especializada. A própria rua, o muro, os corredores ou as plataformas em que este cartaz é afixado também confere eficácia enunciativa e pragmática. O percurso dos espectadores potenciais, suas esperas e suas competências modais e passionais, segundo ele, também fazem parte do entorno e precisam ser levados em conta numa análise:

Interessar-se pela afixagem não é apenas passar do texto-enunciado ao objeto, mas ao conjunto da situação semiótica que permite ao cartaz funcionar segundo as regras de seu próprio gênero e regular principalmente sua interação com os percursos e os usos dos espectadores (FONTANILLE, 2005, p. 19).

Todas essas considerações acerca da afixagem de cartaz podem ser transportadas para a análise da foto de Wilton Junior, já que tão importante quanto o objeto em si, a imagem fotográfica, é o lugar em que ela se insere, o jornal $O$ Estado de $S$. Paulo. Por isso, as considerações que seguem abordarão o papel do veículo de divulgação da foto, a diagramação do jornal, e a expectativa tradicional dos leitores - temas que envolvem a ética jornalística, quer dizer, os princípios ideais que regem essa prática.

De acordo com com Fraser Bond, "a palavra jornalismo significa, hoje, todas as formas nas quais e pelas quais as notícias e seus comentários chegam ao público" (BOND, 1962, p. 15). Com base nessa definição, é possível atribuir à imagem - e, de modo mais específico, à fotografia - o mesmo estatuto de texto que se atribui à linguagem verbal no jornal. Conforme explica Diana 
Barros, um texto define-se de duas formas que se complementam: 1) "pela organização que faz dele um "todo de sentido"; 2) "como objeto da comunicação que se estabelece entre um destinador e um destinatário" (BARROS, 2001, p. 7). Assim, tais linguagens não apenas gozam de relevância e responsabilidade equivalentes, mas também compartilham a capacidade de engendrar discursos.

Em semiótica, o termo "discurso" pode ser definido como "o plano do conteúdo do texto", isto é, os valores que o enunciador busca transmitir ao seu enunciatário. Nesse respeito, convém perguntar: que valores norteiam a prática jornalística, especialmente a do jornal O Estado de S.Paulo, em que foi veiculada a foto Touché, de Wilton Junior?

Diversos textos acadêmicos e também definições formuladas em manuais de redação concordam com Juarez Bahia, que conceitua o jornalismo como "uma forma de registro, pautado na transmissão de informações, fatos ou notícias de modo exato e claro" (BAHIA, 1964, p. 130). No trabalho desenvolvido por Biroli e Miguel (2012), por exemplo, várias referências utilizadas apontam para a objetividade como o valor basilar do jornalismo, conferindolhe legitimidade e, ao mesmo tempo, diferenciando-o de outros discursos e práticas sociais. Mas, o que signfica exatamente essa objetividade e que impacto o cumprimento ou o descumprimento desse princípio pode ter sobre uma dada prática situada no âmbito da informação? Os autores explicam:

No mundo moderno, o ideal da objetividade corresponde, grosso modo, à valorização do acesso a uma verdade que estaria contida na realidade exterior e que seria independente dos processos cognitivos. No jornalismo, ele impõe, em primeiro lugar, um compromisso com a busca por este dever, que é de cada profissional e que é reforçado pelo controle mútuo e pelos códigos da deontologia jornalística. Também para o público, o bom jornalismo é aquele que sustenta esse compromisso, fornecendo informações confiáveis (BIROLI; MIGUEL, 2012, p. 23). 
Em outros termos, a objetividade é tida como o resultado de um esforço de suspensão do sujeito mediador - o que significa transcender não apenas os interesses parciais alheios que eventualmente podem se colocar em conflito, mas também os do próprio intermediário, sua perspectiva social e política. Quanto mais de perto se segue esse ideal, mais respeitada se torna a prática em questão, ajuizada pelo público como um exemplar de "bom jornalismo" - julgamento que se estende tanto para os profissionais como para os veículos de comunicação que transmitem tal informação.

Conforme Biroli e Miguel, o princípio de objetividade é apresentado como norteador do jornalismo desde os primeiros manuais e compêndios de normas sistematizados no país, que despontaram entre as décadas de 1930 e 1950. Nesse âmbito, a fidelidade aos fatos deveria, inclusive, "orientar a reorganização das práticas jornalísticas, propiciada pelas inovações tecnológicas e pela produção da notícia em escalas industriais" (BIROLI; MIGUEL; 2012, p. 24). Ao longo das décadas seguintes e das mudanças que a objetividade como valor norteador impetrou na rotina das redações, desde os procedimentos padronizados com vistas à imparcialidade ao consequente distanciamento entre a prática de um jornalista e a de um literato ou militante político, muitas críticas trataram de expor os limites do ideal a ser perseguido. Conforme resumiram Hohlfeldt e Valle,

É preciso destacar que o jornalismo é e sempre será uma atividade de cunho parcial. Isto significa dizer que, nas coberturas e nos registros que um veículo de comunicação faz, sempre existirá, por menos que profissional queira, a parcialidade de quem o executa, seja através do repórter, do redador, do fotógrafo e das demais funções, bem como através da linha editorial que determinado veículo assume (HOHLFELDT; VALLES, 2008, p. 61-62).

Apesar da percepção de que a anulação completa do mediador é impossível, a busca pela objetividade persiste no âmbito 
da prática jornalística e pode ser constatada nos manuais de redação e estilo. No caso do jornal O Estado de S. Paulo, a força norteadora desse ideal aparece já nas instruções gerais que o manual fornece aos jornalistas, como pode ser observado nos itens de número 1, 20 e 21:

1 - Seja claro, preciso, direto, objetivo e conciso [...] não é justo exigir que o leitor faça complicados exercícios mentais para compreender o texto.

20 -Faça textos imparciais e objetivos. Não exponha opiniões, mas fatos, para que o leitor tire deles as próprias conclusões. [...]

21 - Lembre-se de que o jornal expõe diariamente suas opiniões nos editoriais, dispensando comentários no material noticioso. As únicas exceções possíveis: textos especiais assinados, em que se permitirá ao autor manifestar seus pontos de vista, e matérias interpretativas, em que o jornalista deverá registrar versões diferentes de um mesmo fato ou conduzir a notícias segundo linhas de raciocínio definidas com base em dados fornecidos por fontes de informação não necessariamente expressas no texto (MARTINS, 1997, p. 15, 17, grifo do autor).

Como se pode observar, há um direcionamento bastante preciso, que busca conduzir o veículo a um tipo específico de jornalismo. Nesse sentido, no livro Técnicas de codificação em jornalismo (1991), Mário Erbolato chama a atenção para três aspectos fundamentais da divulgação de um fato: informação, interpretação e opinião. Destes, resultam três práticas diferentes:

a) jornalismo informativo: ênfase à notícia objetiva, à informação pura, imparcial, impessoal e direta; limita-se a narrar os fatos;

b) jornalismo opinativo: representado atualmente pelos editoriais e em alguns artigos e crônicas, expressa a opinião do seu autor sob o ponto de vista expresso, fazendo juízo sobre o assunto;

c) jornalismo interpretativo: é o desdobramnto e o aprofundamento da notícias, graças à investigação, cujo 
desenvolvimento se deve muito à tecnologia. Em décadas anteriores, um arquivo fotográfico e uma biblioteca constituíam o setor de pesquisa de um jornal. Hoje, com as tecnologias da informática, a investigação foi facilitada e ampliada, sem a necessidade de o repórter ir à rua, embora o jornalismo sempre deva ser desenvolvido, evidentemente, com o repórter atuando junto às fontes e aos acontecimentos [...](ERBOLATO, 1991 apud HOHLFELD; VALLES, 2008, p. 60).

Comparando os trechos destacados do Manual de Redação e Estilo e a citação de Erbolato, é possível associar a prática do jornal $O$ Estado de S. Paulo ao jornalismo de cunho informativo - com exceção dos espaços destinados à interpretação e à opinião, como certos textos assinados e os editoriais. Embora alguns jornais possam ter notoriedade pela obliquidade, digamos assim, de suas manchetes e matérias ${ }^{1}$, resvalando mais para a função de entretenimento do que para a de informação, a linha do jornal $O$ Estado de São Paulo segue os moldes tradicionais, o que coloca sua produção jornalística no eixo que Floch (1990) denominou de referencial. E é isso o que o leitor, cultivado pelo jornal, espera encontrar em suas páginas. Mas, em vez da objetividade, a foto revela a busca deliberada do fotorepórter em construir um ponto de vista sobre o contexto:

Sempre que saio para um evento político busco uma foto que possa retratar o momento. Nem sempre é possível transmitir uma informação desse tipo numa imagem, mas às vezes acontece. A presidente está com problemas políticos em sua própria base, e a foto dá bem essa

\footnotetext{
1 O mais notório jornal "oblíquo", apesar de já extinto, é o Notícias Populares. Dentre suas principais características estavam a distorção, o exagero e a criação de fatos com o intuito de produzir manchetes ambíguas, incompletas ou estranhas, capazes de despertar a curiosidade do público. A título de exemplo, seguem algumas delas: "Traficantes derrubam avião no Jd Ângela" (neste caso, avião é uma gíria para os garotos que fazem o fluxo de drogas entre traficante e consumidor); "Bixa põe rosquinha no seguro"; "Aumento de merda na poupança"; "Broxa torra o pênis na tomada"; "A morte não usa calcinha", "Churrasco de vagina no rodízio de sexo". (NOTÍCIAS..., 2012).
} 
dimensão, já que a mostra sendo atacada por trás. Já fui para a Aman pensando em que tipo de foto poderia retratar essa questão (PHOTO MAGAZINE, 2011, p. 72).

O punctum gerado pela foto, portanto, pode também ter sido despertado em vista da promoção de uma imagem oblíqua, cuja essência é a negação da referencialidade, num veículo que prima editorialmente por esse valor. Um estranhamento ou incômodo que certamente não ocorreria num jornal como o já extinto Notícias Populares, dado o diferente tipo de contrato que se estabelece entre o veículo e o público.

Soma-se a isso a disposição da foto no jornal (Figura 2), colocada numa espécie de "link" com a manchete "Desconfiado de Dilma, PMDB faz plano para 2014" e sua linha fina "Descontentes com o tratamento do PT e receosos sobre o empenho da presidente para manter aliança, dirigentes preparam candidaturas ". De modo que a imagem da presidenta Dilma sendo transpassada não só é compartilhada com a citada manchete como esta ganha primeiro plano em relação à nota "Honras militares", evento originário da fotografia. Esse sentido decorre da posição topológica que cada notícia assume na página, respectivamente "superior" vs. "inferior". Mas também pela posicão "intermediária” da imagem e, sobretudo, pelo efeito de separação que o traço em vermelho, colocado entre a imagem e a nota do evento, cria ao desvincular a fotografia da nota inferior e vinculá-la à manchete superior. Todas essas escolhas confirmam as considerações de Gruszynski sobre a influência que a diagramação pode exercer sobre a compreensão do enunciatário: "as estratégias de composição visual do impresso orientam a leitura, unindo alguns elementos e destacando outros, dimensionando a hierarquia dos dados, propondo conexões e sentidos" (GRUSZYNSKI, 2010, p. 14). Nesse aspecto, novamente observamos incongruência entre o direcionamento editorial do jornal, que preza pela objetividade e sua função referencial, e o sentido oblíquo que emana da diagramação da página. 


\section{Considerações Finais}

Neste trabalho, buscamos analisar a foto Touché, feita por Wiilton Junior para o jornal O Estado de S. Pauio. Em Zûii , data em que a imagem foi publicada no jornal, o perigo em torno do chamado "fogo amigo" já vinha sendo discutido na mídia, especialmente com a queda de ministros a partir de denúncias de corrupção vindas da própria base aliada do governo, que acabavam por enfraquecer a gestão da presidenta.

O cerimonial da entrega dos espadins aos cadetes do primeiro ano pareceu então ao fotorepórter ser o cenário propício para a criação de uma imagem que representasse essa "apunhalada pelas costas" - o fato de se tratar de um evento militar, lembrando que Dilma já foi perseguida e torturada pelo regime, reforçava o sentido de que a gestão da presidenta não era bem aceita, apenas tolerada, e que a qualquer momento ela poderia sofrer realmente um golpe. Assim, surgindo a oportunidade, Wilton Junior fez o "click". Na definição de Barthes (1984), um verdadeiro "achado fotográfico", dada a colocação do fotojornalista no "lugar certo" e na "hora certa".

Apesar da objetividade ser uma das principais características do registro automatizado de imagens, motivo pelo qual a fotografia alcançou o status de imagem-documento e foi amplamente utilizada em jornais, buscamos mostrar, num primeiro momento, como em Touché todos esses pressupostos de referencialidade foram traídos a partir da técnica de achatamento dos planos. Enquanto diversos jornais se valeram de aparatos automáticos para produzir uma imagem referencial, no Estadão a fotografia como dispositivo referencial fornecia uma imagem oblíqua.

Num segundo momento, nos voltamos para a situação ou âmbito em que a foto de Wilton Junior havia sido publicada, o que incluiu o jornalismo como gênero, $O$ Estado de S. Paulo como veículo de divulgação e também a diagramação da página em que a foto foi inserida. Embora a objetividade seja apontada 
como um valor norteador para o jornalismo de modo geral e um ideal perseguido pelo próprio O Estado de S. Paulo, conforme estabelecido em seu manual de estilo e redação, o veículo não apenas se valeu da imagem produzida pelo fotorepórter como a dispôs num arranjo ou organização visual também oblíquo. Com isso, tanto o dispositivo fotográfico como o veículo foram subvertidos em sua função referencial.

É possível que muitos leitores tenham observado a foto da presidenta Dilma sem sentir qualquer emoção, eufórica ou disfórica, fazendo apenas um reconhecimento dos personagens, do cenário e da ação - uma leitura pautada apenas no studium, conforme explicou Barthes (1984). E é nesse sentido que se pode considerar que o punctum depende única e exclusivamente do sujeito. Em outras palavras, nenhum recurso pode garantir a sensibilização de quem fita a imagem. Mas, se não é possível garantir, vimos que certas estratégias podem ao menos predispor o sujeito, como uma armadilha capaz de fisgar sua emoção.

\section{Referências}

BAHIA, Juarez. Jornal, história e técnica. São Paulo: Martins, 1964.

BARROS, Diana Luz Pessoa. Teoria semiótica do texto. São Paulo: Ática, 2001.

BARTHES, Roland. A câmara clara: nota sobre a fotografia. Rio de Janeiro: Nova Fronteira, 1984.

BIROLI, Flávia; MIGUEL, Luis Felipe. Orgulho e preconceito: a "objetividade" como mediadora entre o jornalismo e seu público. Opinião Pública, Campinas, v. 18, n. 1. p. 22-43, 2012.

BOND, Fraser F. Introdução ao jornalismo. Rio de Janeiro: Agir 
Editora, 1962.

DOMINGOS, João. Desconfiado de Dilma, PMDB faz plano para 2014. O Estado de São Paulo, São Paulo, 20 ago. 2011. Disponível em: < http://blogs.estadao.com.br/radar-politico/2011/08/23/ estadao-desmente-foto-montada $>$. Acesso em: 5 mar. 2017.

FLOCH, Jean-Marie. Sémiotique, marketing et communication. Paris: PUF, 1990.

FONTANILLE, Jacques. Significação e visualidade: exercícios práticos. Porto Alegre: Sulina, 2005.

GRUSZYNSKI, A. Jornal impresso: produto editorial gráfico em transformação. In: CONGRESSO BRASILEIRO DE CIÊNCIAS DA COMUNICAÇÃO, 33., 2010, Caxias do Sul. Anais... Caxias do Sul: Intercom - Sociedade Brasileira de Estudos Interdisciplinares da Comunicação, 2010.

HOHLFELDT, Antonio; VALLES, Rafael Rosinato. Conceito e história do jornalismo brasileiro na "Revista de Comunicação". Porto Alegre: EDIPUCRS, 2008.

TCMARTINS, Eduardo. Manual de redação e estilo. 3. ed. São Paulo: O Estado de S. Paulo, 1997.

NOTÍCIAS populares. In: Wikipédia. Disponível em: $<\mathrm{http}: / /$ pt.wikipedia.org/wiki/Not\%C3\%ADcias_Populares>. Acesso em: 5 mar. 2012.

PHOTO MAGAZINE. Fotojornalismo. Balneário Camboriú: Editora Photos, 2011.

STUCKERT FILHO, Roberto. Entrega de espadins na Academia Militar das Agulhas Negras. 2011. Disponível em: <http:// 
www2.planalto.gov.br/centrais-de-conteudos/imagens/entregade-espadins-na-academia-militar-das-agulhas-negras/entregade-espadins-na-academia-militar-das-agulhas-negras.jpg/view $>$. Acesso em: 5 mar. 2017.

TABAK, Bernardo. Dilma participa de cerimônia de entrega de espadins a cadetes no Rio. 2011. Disponível em: <http://g1.globo. com/politica/noticia/2011/08/dilma-participa-de-cerimonia-deentrega-de-espadins-cadetes-no-rio.html $>$. Acesso em: 21 jun. 2017. 